\title{
La sociología de la vida cotidiana de Ágnes Heller: importancia y vigencia para los estudios sociales contemporáneos
}

\author{
Ulises Bernardino Márquez Pulido \\ Universidad Autónoma de Barcelona \\ ulises.mar.pu@gmail.com
}

Recepción: 04-06-2020

Aceptación: 09-10-2020

Publicación: 20-01-2021

\section{Resumen}

En este trabajo hacemos una interpretación crítica del pensamiento sociológico de Ágnes Heller, especialmente de sus estudios de la «vida cotidiana». En principio, llevamos a cabo un primer acercamiento a sus investigaciones y contextualizamos históricamente sus escritos, delimitamos las obras a estudiar, específicamente los textos que abordan el tema de la cotidianidad, y luego hacemos un recuento de su «trayecto biográfico» y de sus principales experiencias que impulsan sus estudios. En un segundo momento, presentamos nuestras interpretaciones sobre sus tesis, sus problemáticas y relevancia en su contexto sociohistórico, los principales conceptos, categorías y rasgos que propone para caracterizar lo cotidiano. Concluimos que investigar la importancia de la "vida cotidiana» es una de las preocupaciones centrales de la obra de Heller. También planteamos que profundizar y recontextualizar sus interpretaciones resulta de radical importancia para la comprensión de nuestras sociedades contemporáneas y, en este sentido, mencionamos algunas de las problemáticas que consideramos relevantes y vigentes para nuestra época y que merecen ser recuperadas críticamente, y proponemos unos interrogantes que nos suscita su obra. A lo largo del escrito, vamos observando su reinterpretación del pensamiento de Marx, su distanciamiento del comunismo soviético, del socialismo de su país y del marxismo ortodoxo que dominaba en su época, y además destacamos la relación entre sus experiencias biográficas y sus preocupaciones teóricas.

Palabras clave: marxismo; alienación; capitalismo; socialismo; revolución; política 
Abstract. Ágnes Heller's sociology of everyday life: Importance and validity for contemporary social studies

In this paper I present a critical interpretation of Ágnes Heller's sociological thought, I focus on her studies of «everyday life». I begin with an approach to her research and historically contextualize of her writings, I delimit the works that I am going to study, specifically her texts where she reflects on the everyday. I conclude that the study of «everyday life» is one of Heller's central concerns, I suggest that it is of radical importance to deepen and recontextualize her research for the understanding of our contemporary societies. I mention some problems that I consider valid for our time and I suggest some questions which inspire me from her work. In the development of my writing I observe Heller's reinterpretation of Marx, her separation from the Soviet communism, from the socialism of her country and from the orthodox Marxist thought which dominated in her time, I highlight the relationship between her personal experiences and her theoretical problems.

Keywords: marxism; alienation; capitalism; socialism; revolution; politics

\section{Sumario}

\section{Introducción}

1. Aproximaciones al «trayecto biográfico» de Ágnes Heller

2. Antecedentes y presupuestos teóricos:

la teoría de las objetivaciones, la ciencia y el arte

3. De la teoría de las objetivaciones a la Sociología de la vida cotidiana
4. Desarrollo del concepto: historia, valores y "vida cotidiana»

5. Necesidades, revolución

$\mathrm{y}$ "vida cotidiana"

Conclusiones

Financiamiento

Referencias bibliográficas

\section{Introducción}

Ágnes Heller fue una de las integrantes más conocidas de la Escuela de Budapest, fundada en 1956 por György Lukács, y una de las más activas en la producción y publicación de su pensamiento científico. Sus investigaciones sobre la "vida cotidiana» fueron tema de discusión y debate en el ámbito académico internacional, influenciaron movimientos sociales y políticos en distintas partes del mundo, y en su país le constaron la persecución política, el hostigamiento y finalmente su autoexilio.

De manera general, los especialistas en Heller, como Ángel Aguirre (1996) ${ }^{1}$ y Antonio Pérez (2005), dividen su obra en dos grandes etapas: la primera, durante su vida en Hungría, que va de 1950 a 1978; y la segunda de 1979 en adelante. ${ }^{2}$

1. En su larga introducción al texto de Heller Una revisión de la teoría de las necesidades, Ángel Aguirre contextualiza el pensamiento de la filósofa y plantea una serie de críticas sobre su teoría de las necesidades que ella trata de aclarar (Heller, 1996).

2. Otro especialista, Ángel Prior, estudia la obra de Heller sobre la base de su biografía. Así, divide su pensamiento en tres etapas: desde su nacimiento, en 1929, a 1977; de 1978 a 1986, cuando vivió en Australia, y de 1986 en adelante, cuando vivió en Estados Unidos y regresó a Hungría (Prior, 2002). 
Estos autores coinciden en que a partir de su salida de Hungría hay un cambio en sus reflexiones filosóficas. Según Pérez, abandona el marxismo para dirigirse hacia la filosofía de Kierkegaard y, según Aguirre, hacia la filosofía de Kant.

De acuerdo con Pérez, la primera etapa está marcada por cuatro grandes temas que atraviesan las preocupaciones filosóficas de Heller y que conforman un conjunto teórico: la ontología de la praxis, la axiología, la ética y la antropología. El mismo autor comenta que después de su exilio crece el descontento de Heller con el socialismo y con el propio Marx, lo que marca un viraje en su reflexión para abandonar el gran «metarrelato» de la historia, reivindicado por el marxismo oficial, reformular su teoría de las necesidades e inclinarse hacia el liberalismo y la socialdemocracia. Por nuestra parte, pensamos que ella abandonó el gran "metarrelato" a partir su texto Historia y vida cotidiana, de principios de la década de 1970, y que otro tema central en su obra, principalmente en la primera etapa, es el estudio de la «vida cotidiana», que dicho autor no menciona.

Si bien Aguirre reconoce que hay transformaciones en el pensamiento de Heller a partir de su exilio, encuentra que hay una cierta continuidad en toda su obra posterior a 1978. Él observa cuatro grandes temas que comprenden de manera general el pensamiento de la filósofa: el proyecto de una antropología social, la teoría sobre la "vida cotidiana», la formulación de una filosofía política y una reflexión sobre la ética.

En este trabajo no vamos a profundizar en el estudio de toda la obra de Heller, lo que rebasaría los límites del espacio que tenemos, sino que trataremos de comprender de manera crítica cuál es su concepto de "vida cotidiana» y qué importancia tiene en el conjunto de su pensamiento científico. Para ello, los principales problemas que planteamos abordar son los siguientes: ¿qué entiende Heller por «vida cotidiana» y qué importancia le otorga en los procesos históricos y los cambios de una sociedad?, ¿cuáles son los principales rasgos que destaca para caracterizar lo cotidiano?, ¿algunas de sus reflexiones son vigentes para realizar estudios sociológicos de la cotidianidad en nuestras sociedades?

Aquí también consideramos, junto con Aguirre y Pérez, que hay dos grandes períodos en la vida intelectual de Heller: de 1950 a 1978 y de 1979 a 2019. Pero nuestra hipótesis es distinta, ya que postulamos que, cuando sale de Hungría, al mismo tiempo que hay cambios en sus posturas teóricas, también hay una continuidad en sus preocupaciones filosóficas. Si bien es cierto que llega a romper con los grandes preceptos del marxismo y del socialismo, nunca abandona la crítica de la sociedad capitalista, ni deja de buscar las estrategias de transformación de la sociedad alienada. Además, planteamos que su reflexión sobre la «vida cotidiana» resulta un aspecto central, quizá uno de los principales, de todo su pensamiento.

Para realizar nuestro análisis, elaboraremos una interpretación crítica de su obra, especialmente de los siguientes textos: Historia y vida cotidiana (1972), Hipótesis para una teoría marxista de los valores (1974), Teoría de las necesidades en Marx (1978), Sociología de la vida cotidiana (1987), La revolución de la vida 
cotidiana (1998), Una revisión de la teoría de las necesidades (1996). Secundariamente, recurriremos a otros de sus estudios y a investigadores que han hecho interpretaciones sobre su pensamiento.

Es importante mencionar que prácticamente toda su reflexión explícita sobre la «vida cotidiana» la realiza en su primer período intelectual, cuando vive en Hungría y bajo los influjos del proyecto de la Escuela de Budapest, a excepción de Una revisión de la teoría de las necesidades. Los trabajos mencionados fueron escritos y publicados antes de 1978, lo que significa que sus preocupaciones están fuertemente marcadas por el ambiente político de la época, por esto nos parece importante describir brevemente su «trayecto biográfico" ${ }^{3}$ (Duch, 1998), ya que sus reflexiones se comprenden con mayor profundidad si consideramos sus experiencias personales en su contexto sociohistórico.

\section{Aproximaciones al «trayecto biográfico» de Ágnes Heller}

Ágnes Heller nació en 1929 en Budapest, en el seno de una familia judía. Durante su infancia y adolescencia sufrió la persecución del régimen nacionalsocialista y, cuando ella tenía 15 años, su padre fue llevado a Auschwitz, donde murió. Ella y su madre lograron escapar y sobrevivir clandestinamente. Terminada la Segunda Guerra Mundial, entre 1945 y 1947 hubo elecciones en Hungría. Ganó la izquierda y muchas fábricas estaban autogestionadas y una mayoría de cultivos agrícolas eran colectivos.

En 1947 Heller ingresó a estudiar física en la Universidad de Budapest, pero pronto cambió sus estudios por la filosofía, después de escuchar una conferencia de Lukács. Con él comenzó su formación humanista en la teoría marxista, y dirigió su atención a problemas políticos, sociales y antropológicos. En ese mismo año se afilió al Partido Comunista Húngaro.

En 1948, cuando comenzó el intervencionismo soviético, la «opresión brutal» no se desató contra un país fascista, comenta Heller, «sino sobre un país que buscaba democracia (...), al cabo de cuatro años de colectivización forzada en el campo y de trabajo forzado en las empresas, como resultado de un proceso de industrialización irracional, el país se vio al borde de la muerte por hambre». (Heller, 1998: 107). ${ }^{4}$

3. El concepto de "trayecto biográfico» de Duch se refiere a la idea de que en el transcurso de la vida de una persona se puede comprender no solo su historia individual, sino una parte de la historia de su época, las formas culturales y los cambios históricos. Dicho concepto está íntimamente relacionado con el de "trayecto hermenéutico», que refiere a los "procesos de interpretación» del mundo social y su relación con la «imagen del ser humano» (Rombach), y con el concepto de «trayecto antropológico» de Gilbert Durand, en el cual se sintetiza la relación entre "formas culturales», "formas simbólicas» y procesos de cambio sociocultural. Para una profundización del concepto de "trayecto biográfico", veáse Duch, 1998.

4. Sobre este período trágico en Hungría, Sándor Márai escribió una novela que retrata los procesos históricos que transformaron este país en el paso de la Segunda Guerra Mundial hasta 1948. Su prosa es profunda y dramática (Márai, 2006). 
Durante la década de 1950, Heller fue alumna y ayudante de Lukács en la universidad, y a principios de 1956 es invitada por Ernst Bloch ${ }^{5}$ a Alemania a un encuentro de filósofos marxistas provenientes de los países socialistas y de los países liberales. En ese mismo año, Lukács fundó la Escuela de Budapest, que tenía como uno de sus principales objetivos hacer una revisión de toda la obra de Marx para formular una reinterpretación de su pensamiento, crítica y distanciada de la versión soviética y estalinista. Nuestra autora se incorporó activamente en este proyecto, pero finalmente, en octubre de aquel año, estalló una revolución popular y se creó un autogobierno del que Lukács formó parte como ministro de Cultura, aunque poco tiempo después, con la invasión militar soviética, fue llevado preso a Rumanía por un año.

Por todos estos acontecimientos, el año 1956 es para nuestra autora el de la "historia comprimida» (Heller), no solo porque fue un momento crucial de su vida y de la vida política y social de su país, y del socialismo en general, sino porque fue una pauta para un quiebre en el pensamiento humanista y en el cambio del concepto de «historia» y «lucha de clases». Heller dice: «Tuvimos la sensación y la conciencia de hacer nosotros mismos la historia» (Heller, 1998: 106). Sin ser meramente una «ilusión», la derrota se volvió para ellos relativa porque aprendieron una gran lección: «que era posible cambiar la vida» (Heller, 1998: 106) y que el proletariado no era el único «sujeto revolucionario».

La primera mitad de la década de 1960 fue para la filósofa una especie de "túnel oscuro de la desesperanza» (Heller, 1998: 107), ya que fue detenida por la policía secreta junto a su marido y acusada de «agitación adversa al Estado", aunque nunca terminó presa ni fue torturada. En la segunda mitad de la década de 1960, se dan en Hungría una serie de reformas políticas impulsadas por el Estado a las que el grupo de Lukács se incorporó activamente. Mientras vivió Lukács, sus discípulos no sufrieron tanta represión como otros socialistas críticos con el régimen soviético. Durante estos años, Heller participó en la Escuela de Verano de Korçula, ${ }^{6}$ organizada por la Escuela de la Praxis, y publicó algunos textos en la revista Praxis, de la cual fue editora.

El año 1968 marcará otro punto importante en la vida intelectual de Heller. Después de la derrota de la revolución húngara de 1956 y el reflujo de los movimientos obreros, surgen en Europa y otras partes del mundo corrientes sociales y estudiantiles que se confrontan directamente con el estado y el mercado. Heller comenta que 1968 es un año que ya preveía como consecuencia

5. Ernst Bloch (1885-1977) puede ser considerado un marxista con un pensamiento «heterodoxo» (Duch), que combina el «mesianismo judío» y el "milenarismo cristiano» para realizar sus reflexiones materialistas. Su biografía es ambigua y contradictoria: desde sus primeras simpatías con el anarquismo hasta el comunismo soviético, con un final marcado por su distanciamiento y la crítica. Lluís Duch recupera su "principio de esperanza» para construir su Antropología de la vida cotidiana y lo une al «principio de responsabilidad» de Hans Jonas (Duch, 2002).

6. La Escuela de Verano de Korçula fue organizada por un grupo de filósofos yugoslavos de corte marxista pero profundamente críticos con el estalinismo y el socialismo soviético. Heller presentó sus trabajos en 1965, 1967 y 1968 (Heller, 1998: 127). 
del cambio del «sujeto revolucionario». Los acontecimientos de aquel año la alentaron a terminar de escribir su Sociología de la vida cotidiana, publicado dos años después, y la inspiraron para proponer su Teoría de las necesidades.

Durante estos años, como parte de su proyecto axiológico, publicó Hipótesis para una teoría marxista de los valores, donde resalta la idea de que el socialismo es un «valor» que puede ser elegido, pero que no es necesariamente la única posibilidad en el curso de la historia. Esta propuesta será profundizada en su texto Historia y vida cotidiana, en el que critica las nociones teleológicas de la historia que ven en el socialismo y el comunismo la culminación evolutiva de la humanidad.

En 1971 murió Lukács, y los miembros de la Escuela de Budapest comenzaron a ser más hostigados por el régimen socialista húngaro. En 1973, en el número 1 de la revista oficial Szociologia, la Comisión Política Cultural del Comité Central del Partido Comunista Húngaro declaraba que un «grupo minoritario" de investigadores había publicado escritos en los que interpretaban de manera «voluntarista» los principios fundamentales del marxismo y esbozaban una "plataforma ideológica revisionista de derechas». Poco después, Heller y los miembros más destacados de la Escuela de Budapest, como Ferenc Fehér, György Márkus y András Hegadüs, fueron expulsados de la Academia Húngara de Ciencias y se les prohibió publicar. A nuestra autora se le impidió impartir clases incluso en secundaria y sobrevivió de las traducciones hasta 1978, cuando consiguió que el Gobierno húngaro le otorgara el pasaporte y se exilió a Australia.

En Australia es recibida en la Universidad de La Trobe, donde impartió clases hasta mediados de la década de 1980 y dio a conocer al mundo su experiencia como filósofa marxista dentro de los países socialistas. Su testimonio fue clave para comprender el carácter totalitario del socialismo soviético. En 1986 migra a Nueva York, donde ocupó la cátedra Hannah Arendt en la Nueva Escuela para la Investigación Social.

Durante la década de 1990 tuvo una vida intelectual bastante activa. Fue columnista del periódico español El País y en 1996 publicó Una revisión de la teoría de las necesidades, a raíz de un debate con Ángel Aguirre. En este trabajo, corrige algunos postulados de su texto de los setenta y nos indica que sus preocupaciones sobre la "vida cotidiana», las "necesidades», la "ética» y la "política» siguen siendo temas de sus reflexiones casi veinte años después de su exilio.

Durante los últimos años de su vida continuó dando conferencias en diferentes universidades del mundo y finalmente pudo regresar a su país. Murió en Balatonalmádi (Hungría) en 2019. Como veremos, su experiencia durante la Segunda Guerra Mundial, su vida bajo la represión del régimen soviético, su participación en los movimientos sociales y su compromiso ético y político con el comunismo influyen fuertemente en sus reflexiones humanistas sobre la «vida cotidiana» y en sus investigaciones científicas a lo largo de toda su vida.

7. Para una aproximación a este período de la Escuela de Budapest, véase Ramón García Cotarelo (1977). 


\section{Antecedentes y presupuestos teóricos: la teoría de las objetivaciones, la ciencia y el arte}

Uno de los antecedentes más importantes que marcan las reflexiones filosóficas de Heller es la obra Estética de Lukács, publicada en 1957. En ese trabajo el filósofo observa que desde la tradición marxista existen muy escasos trabajos sobre la «vida cotidiana» y sobre lo estético, en cambio reconoce en Heide$\operatorname{gger}^{8}$ el principal teórico de la cotidianidad y nunca menciona los trabajos de Henri Lefebvre. ${ }^{9}$ Debido a este déficit que él detecta en el marxismo, se propone como objetivo principal trazar una teoría de lo estético afirmando que la tradición marxista tiene una estética propia, para ello construye su «teoría de las objetivaciones», que será retomada por Heller y que resumimos rápidamente.

Tomando como base los estudios de Ivan Pavlov, ${ }^{10}$ el filósofo de Budapest considera que el lenguaje es un «sistema de señales de segundo orden» (Lukács, 1966: 34), un «reflejo» a través del cual los seres humanos se alzan sobre el mundo para comprenderlo y poder habitarlo. En este proceso se conforman tres grandes tipos de personalidades: «un tipo artístico, un tipo pensador y un tipo medio" (Lukács, 1966: 35).

Para Lukács, el tipo artístico corresponde al «reflejo estético» de la realidad; el tipo pensador corresponde al «reflejo científico» y el tipo medio corresponde a la "vida cotidiana». Los «reflejos» estético y científico conforman dos grandes polos que se han ido diferenciando cada vez más en el curso de la historia hasta alcanzar una relativa autonomía. Entre ambos polos, está la «vida cotidiana», que funciona como una especie de río que corre en las dos direcciones opuestas enlazando arte y ciencia. Los tres «reflejos», el estético, el científico y el cotidiano, representan y aluden a la misma realidad, solo que cada uno lo hace de diferente forma y a veces con grandes contradicciones entre sí.

La ciencia y el arte son dos de las «objetivaciones» más importantes que ha producido el ser humano, pero ambas se ubican fuera de la "vida cotidiana»,

8. El pensamiento de Heidegger es sumamente complejo y tuvo transformaciones a lo largo de su vida. Sus ideas han sido estudiadas en distintas partes del mundo y algunos de sus alumnos más destacados son: Karl Löwith, Hans George Gadamer, Hannah Arendt y Heinrich Rombach. Todos reconocen una deuda con él, y al mismo tiempo le hacen una férrea crítica y marcan un distanciamiento. Su obra más importante sobre el estudio de la «vida cotidiana» es Ser y tiempo (2003), publicada en 1927.

9. Desde nuestra perspectiva, Henri Lefebvre es un pionero en los estudios de «vida cotidiana» desde la tradición marxista. Su obra Crítica de la vida cotidiana, publicada diez años antes que Estética de Lukács, marca una pauta en la reflexión sobre lo cotidiano y establece un programa de investigación que será desarrollado durante por lo menos 30 años. Las obras que consideramos más importantes sobre los estudios de cotidianidad de Henri Lefebvre son las de 1947, 1961, 1973, 1980, 1981, 2013.

10. Ivan Pavlov (1849-1936) nació en Rusia, estudió medicina y fisiología, pero centró sus estudios en psiquiatría y psicología. En 1904 ganó el premio Nobel de medicina por sus descubrimientos sobre los «reflejos», fue marginado por el zarismo y alabado por el régimen soviético, en especial por Lenin. Para una aproximación a su pensamiento, véase Rosa Castillo Jairo (2007). 
pero la cotidianidad es inimaginable sin ellas. ¿Qué caracteriza entonces a la cotidianidad en el pensamiento de Lukács? Decíamos antes que en primera instancia el «lenguaje», pero para el filósofo el lenguaje no puede comprenderse separado del «trabajo» y los problemas del «trabajo», es decir, las relaciones sociales de producción económica, así que lenguaje y trabajo conforman una unidad antroposociológica.

En síntesis, para Lukács la «vida cotidiana» es un «reflejo» que se compone básicamente de «lenguaje» y "trabajo», desde donde se produce el «arte» y la «ciencia», dos de las «objetivaciones» más importantes de una sociedad. Estas últimas pueden influir en comportamientos en la «vida cotidiana», o bien estar totalmente alejadas de ella, pero lo más importante es que en los comportamientos científicos o artísticos, en su distinción y contraposición con el comportamiento cotidiano y en la "vida cotidiana», se realiza el «hombre entero» (Lukács). Entonces, ya que la ciencia y el arte han surgido de la cotidianidad para mejorarla y servirla, cuando pierden su contacto con ella pierden también la justificación de su existencia, es decir, están alienadas.

A partir de aquí, Lukács deja de reflexionar sobre la cotidianidad y se enfoca en estudiar la estética. Por su parte, y partiendo de esta «teoría de las objetivaciones», Heller no estudiará la estética, ni la ciencia, sino lo cotidiano, y tomará como base la tesis del «lenguaje» y del «trabajo» como dos de sus componentes básicos.

\section{De la teoría de las objetivaciones a la Sociología de la vida cotidiana}

Para construir su Sociología de la vida cotidiana, la filósofa no solo parte de Lukács, también reconoce la influencia positiva de Husserl y su concepto «mundo de la vida» (Lebenswelt). Una teoría que rechaza es la de Hegel, específicamente su noción de "espíritu absoluto», porque en ella el «particular», su «vida cotidiana», "solo adquiere significado en la medida en que realiza casi contra su voluntad el espíritu universal» (Heller, 1987: 5).

Otro trabajo que la filósofa refiere es el de Lefebvre (1947), a quien también rechaza porque le parece que reduce la «vida cotidiana» a ser mediadora entre la naturaleza y la «socialidad» del anthropos, por tanto, separa naturaleza y sociedad. Para Heller, la "vida cotidiana» es mucho más que una mediadora, y sus mediaciones son cada vez más con la sociedad y menos con la naturaleza.

A partir de estos precedentes, establece el principio de que la «vida cotidiana» está formada por el "conjunto de actividades que caracterizan la reproducción de los hombres particulares, los cuales a su vez crean la reproducción social» (Heller, 1987: 19). El problema entonces es comprender lo siguiente: ¿̨a qué «actividades» se refiere y cuáles son algunas de las más importantes?, ¿qué es un "particular» y qué significa que se reproduzca?, ¿̨n qué se distingue un "particular» de un «individuo»? Problematizado en conjunto, ¿cuáles son las principales actividades y motivaciones que hacen que el «particular» reproduzca su mundo social reproduciéndose a sí mismo? 


\subsection{Sistemas de usos: "particulan e «individuo»}

En primer lugar, Heller establece que los seres humanos nacen en un mundo que no eligen, que está "ya constituido», tiene una historia, lenguajes, tradiciones, prácticas culturales, es decir, «sistemas de usos». Para poder sobrevivir, cada ser humano debe aprender a utilizar sus propios «sistemas». Así, un "particular» es siempre una persona cultural e históricamente ubicada con unos límites y unas posibilidades más o menos definibles que, en términos de una media, ha conseguido «dominar» sus propios «sistemas de usos».

$\mathrm{La}$ apropiación de los «sistemas de usos» siempre es provisional, los seres humanos los aprenden cada día y pueden crear y aprender nuevos «sistemas», asimismo todos los «sistemas» son dinámicos, cambian. Dicho de otra forma, una vez que el «particular» se ha apropiado de sus «sistemas de usos», tiene la capacidad y la posibilidad, varias veces, de elegir por sí mismo su «ambiente directo, puede escoger un pequeño mundo suyo relativamente nuevo, dentro de límites precisos más o menos amplios» (Heller, 1987: 23).

La "vida cotidiana» se caracteriza por «educar» y «educarse», transmitir usos y adquirirlos, lo que sucede siempre en un "ambiente inmediato»: el mundo cotidiano del "particular», desde el cual se alzan las objetivaciones más elevadas como la ciencia y el arte. Aquí Heller sigue a Lukács en su «teoría de las objetivaciones», pero agrega: «En la vida cotidiana la actividad con la que formamos el mundo y aquella con la que nos formamos a nosotros mismos coinciden» (Heller, 1987: 25-26).

Entonces, el «particular» es todo ser humano singular cuya principal cualidad es su "socialidad», y cultivar esta cualidad es apropiarse de la "vida cotidiana» y sus «sistemas de usos». En este proceso, la conciencia del yo aparece simultánea a la conciencia del «mundo» y no pueden existir separadas. En primera instancia «particular» y «socialidad» coinciden, por eso, para Heller, «la vida cotidiana tiene una historia... es un espejo de la historia» (Heller, 1987: 20). ${ }^{11}$

Para la filósofa de Budapest, la concepción de la conciencia del yo y de la del mundo como simultáneas está ya en autores como Hobbes y Spinoza, según su interpretación. Para ellos, de esta conciencia deben deducirse todas las motivaciones humanas, especialmente la autoconservación del yo, pero, para Heller, la autoconservación del yo tiene ante todo un motivo "genérico", es decir, una "forma específica» de "socialidad», ya que "es la genericidad la que hace comprensible la especificidad de la autoconservación humana» (Heller, 1987: 36) y no los motivos privados del "particular», que ante todo siempre son aprendidos de su propia «socialidad».

11. Vale la pena mencionar que esta concepción se asemeja a la propuesta por Berger y Luckman (2003) cuando fundamentan su «sociología del conocimiento». En su texto La construcción social de la realidad, publicado en 1966, observan que el "calendario» es el «tiempo intersubjetivo" por excelencia de la "vida cotidiana», ya que en él se armoniza la interioridad (subjetiva) con la exterioridad (social). Mencionan que «el tiempo individual se sitúa a la vez en un tiempo histórico que se impone sobre la biografía en conjunto» (Berger y Luckman, 2003: 44). 
Heller reconoce que la «unicidad» y la «particularidad» de cada ser humano son ciertamente hechos "ontológicos», pero esto no significa que la unicidad represente el «en-sí» y el "para-sí» de la esencia del anthropos, pues lo «irrepetible», lo «único», se realiza en la actividad "genérica» (humana), además, la conciencia del "yo" no es independiente de la conciencia del "nosotros», incluso en la exacerbación de la "particularidad». Al contrario, la "particularidad» es producida por la "totalidad del sistema concreto", que es el ámbito de la cotidianidad; defender la "particularidad» es también defender el sistema concreto. ${ }^{12}$

Para Heller, sobre la base de la «particularidad» se alza la «individualidad»: el "particular» deviene en «individuo», lo que significa una relación cada vez más consciente con la «genericidad». Aquí tenemos que mencionar que Heller plantea una distinción radical entre el «individuo» como ser consciente de su época y su historia, de su "genericidad», y el «individualismo» como ideología propiamente liberal y capitalista. Para Heller, la conquista del «individuo» como un yo autónomo de la «socialidad» es uno de los grandes logros de la cultura occidental; la «individualidad» es una posibilidad de la "genericidad» y es «representativa», y esto es importante; «del desarrollo genérico» de una sociedad concreta, representa el desarrollo de la "esencia humana» en un momento histórico y cultural.

En síntesis, para Heller, la «esencia humana» es la «socialidad», que en primera instancia es idéntica a la "particularidad» y es la base de cualquier desarrollo de «valor», pero esta «esencia» no es algo que proviene de la constitución biológica del Homo sapiens, ni surge antes de la «vida cotidiana», sino que se confirma, se desarrolla, o limita en la cotidianidad y a través de los procesos históricos, individuales y colectivos, no es un a priori, sino un a posteriori.

Para la filósofa, el «individuo» que supera la condición de «particular» es representativo de su época, es decir, puede llegar a encarnar el "máximo» de desarrollo de la «genericidad» de un tiempo histórico concreto, pero no ofrece una imagen de la totalidad de la estructura social. En sociedades complejas, como las modernas, el «individuo» no puede representar ese «máximo», o solo muy aproximadamente. Incluso así, este «individuo» es llamado por Heller un "ente consciente genérico», es decir, que representa al género humano de su tiempo histórico, para el cual su vida es conscientemente «objeto», o sea, interviene directamente, o al menos lo intenta, en los procesos económicos, políticos e históricos de su época.

Resumiendo, Heller considera que la «vida cotidiana» está articulada en un primer momento por los «sistemas de usos» (tradiciones, prácticas culturales,

12. Esta noción ha hecho pensar a algunos autores, como Alicia Lindón (1999), que para Heller la "vida cotidiana» es el ámbito permanente de la alienación, pero para la filósofa de Budapest es posible una cotidianidad no alienada, donde se conquiste la individualidad, y esa es la perspectiva del comunismo que practicaba en esa época. Más adelante regresaremos a esta discusión. 
lengua) que reproduce el "particular», el cual en principio es idéntico a su «socialidad», en cambio, el «individuo» que supera su condición de "particular» contribuye al desarrollo de la «esencia» humana, es un «ente» consciente de su genericidad.

Después de establecer su noción de "sistemas de usos», nuestra autora regresa a los trabajos de Lukács para agregar como componente importante de la cotidianidad el «trabajo», siempre unido al «lenguaje». Sobre este elemento tiene sus propias interpretaciones, ya que resulta central en toda la teoría marxista. A continuación, intentaremos sintetizar las que consideramos sus principales tesis.

\subsection{Trabajo: work, labour y moral}

De acuerdo con nuestra autora, Marx distinguía entre el trabajo como work y como labour. Como work, es una actividad genérica que produce «valores de uso", satisface una necesidad social cuyo resultado es la producción material y total de la sociedad, está guiado por el «trabajo concreto" y no por el conjunto de las objetivaciones. Como labour, es una actividad de la "vida cotidiana», centro neurálgico de la organización de las demás actividades (educación, moral), no implica la alienación, y sin embargo, para Marx, labour, en el capitalismo, es sinónimo de trabajo alienado.

Lo importante en esta distinción es que los dos momentos del trabajo corresponden a un único proceso, y sobre el work, destaca Heller, es posible tener muchas ideas como lo hizo Marx (esclavismo, feudalismo, capitalismo), pero independientemente de su configuración histórica este siempre permanecerá en el ámbito de la «necesidad», es decir, "presupone que los seres humanos no pueden sobrevivir sin contribuir, de algún modo, a la producción de bienes... el trabajo como necesidad presupone una actitud moral hacia el labour de los individuos libres, sin trabajo no podría reproducir su libre individualidad» (Heller, 1987: 127).

El trabajo como work y como labour contiene diferentes motivaciones que se expresan en el "particular» de distintas formas y son de índoles diversas, pero en general refieren a la moral, la estética y la ética que han interiorizado en el transcurso de su «vida cotidiana». Dado que ningún «trabajo» es neutral, sino que produce necesariamente una "forma social», a Heller le interesa destacar sobre todo la «moral», su contenido, así como la regulación de las motivaciones y la elección del «valor», su relación con las normas y la alienación. Resumámoslo rápidamente.

«La moral es la relación entre el comportamiento particular y la decisión particular por un lado y las exigencias genérico sociales por otro» (Heller, 1987: 132), es ante todo una "actitud práctica» que no es "autónoma», sino que pertenece a diferentes esferas, no es ideología, aunque contenga un momento y un aspecto ideológico. En general, la filósofa define cuatro grandes aspectos de la moral: 1) subordinación de las motivaciones particulares por lo social;2) elección de fines y contenidos (valores); 3) constancia 
en la subordinación y 4) capacidad de aplicar estas exigencias en el plano concreto. ${ }^{13}$

Como no tenemos espacio para detenernos a desarrollar toda su concepción de la "moral», solo mencionaremos dos ideas importantes que destaca. La primera es que se distingue de la ética. Para Heller, la ética es una elevación sobre la moral, una "mimesis" de la moral que puede surgir como un "código", la filosofía, por ejemplo. En ella los «juicios morales» son la suma de los «conceptos morales», inverso a la moral, que es ante todo una "actitud práctica». ${ }^{14}$

La segunda idea es la relación entre la moral y la «legalidad». A diferencia de Kant, para quien la moral es subjetiva y la legalidad es objetiva, Heller establece la idea que hay una copresencia de la legalidad en la moralidad y viceversa. El carácter normativo puede estar presente en la subjetividad, y no hay normas que no contengan un momento subjetivo, incluso negándolo. Para el "particular", sin embargo, la moralidad es interna, mientras que la legalidad es externa; para el «individuo» es importante sincronizar ambas cultivando las cualidades de valor positivo.

Además, Heller distingue entre normas abstractas que representan la genericidad universal y las concretas que expresan determinados sistemas de exigencias sociales. El «particular» se apropia simultáneamente de ambas, pero la «vida cotidiana» es especialmente el lugar donde se validan las normas concretas; las abstractas se verifican a lo largo de la historia. Así, la filósofa distingue entre «sitte» (del alemán, que quiere decir usanza y moral) como «sistema concreto de usos de la moral» y la "moral abstracta», el sistema de normas generales portadoras de valores genéricos (libertad, igualdad, solidaridad) surgidos en el curso de la historia del género humano. La discrepancia entre «usos de la moral» y «moral abstracta» expresa, en el plano de la ética, la discordancia entre el "particular» y el «individuo», o la divergencia entre las clases sociales y los valores genérico-universales validos en este momento histórico específico.

Con la distinción entre "moral abstracta» y «moral concreta», Heller establece su concepción de alienación de la moral, cuando «la moral abstracta no puede coincidir totalmente con ninguna usanza concreta... es una manifestación de la alienación de la moral» (Heller, 1987: 147). O sea, cuando las exigencias concretas no toman en cuenta a los sujetos y se imponen, casi como un castigo, tanto al "particular» como al «individuo», negando los valores abstractos, Heller escribe: «Las fuerzas sociales más negativas, como el fascismo y

13. Con relación al primer aspecto (subordinación de las motivaciones particulares por lo social), nos parece que es una idea que ya aparece en Freud y su análisis de la formación del yo, el ello y el superello. En general, para Freud, las pulsiones son «reprimidas» por la "cultura» para evitar que domine el «eros» o el «tánatos» y se formen personalidades psicóticas o perversas, con ello se establece un código «moral» (Freud, 2001).

14. Vale la pena mencionar, por contraste, que en la Antropología de la vida cotidiana de Lluís Duch (2002) la moral es un "código» preestablecido, un a priori, por ejemplo, los diez mandamientos; en cambio, la ética es una "actitud práctica», un a posteriori, que se resuelve principalmente ante los dilemas de la «vida cotidiana» y siempre frente al «rostro del otro» (Lévinas), e implica una «decisión responsable». Véase, Lluís Duch (2000; 2002). 
el nazismo, son las que niegan la moral abstracta en nombre de las costumbres concretas, oponiéndose conscientemente al desarrollo de valores genéricos» (Heller, 1987: 151).

La relación entre «moral» $\mathrm{y}$ «trabajo» cobra una importancia central en el pensamiento de Heller, y es relevante sobre todo en la modernidad, donde el trabajo y la moral alienados se imponen de manera coercitiva sobre el conjunto de la sociedad, «particulares» e «individuos». Esta situación se aplica a toda actividad cotidiana y esto se debe en gran medida a que las exigencias de la «moral concreta» que articulan el modo de producción capitalista se imponen a la sociedad en general. A pesar de esta situación, la filósofa reconoce la posibilidad de construir una "vida cotidiana" no enajenada, que sincronice ambas morales. ${ }^{15}$

Resumiendo, el «trabajo», el «lenguaje» y los «sistemas de usos» se ubican en el plano de la "particularidad», en el cual el work es capaz de desarrollarse sin problemas y en los tres (trabajo, lenguaje, sistemas de usos) no existe necesariamente una relación consciente con la genericidad. Es el «individuo», consciente de su "genericidad", el que decide, dentro de unos límites más o menos amplios, si reproduce «los sistemas de usos», o los cambia o construye nuevos, si mantiene la forma del work o la transforma; es el «individuo» el que conquista los valores abstractos de libertad, igualdad, solidaridad.

Desde una óptica helleriana, podríamos decir que para que la sociedad supere la alienación capitalista es necesario superarla primero individualmente en la «vida cotidiana», postura que choca fuertemente con las teorías del marxismo ortodoxo de su época, que postulaban una interpretación inversa, donde el estado y las instituciones tienen el papel principal en el proceso de superación de la alienación. En este punto nos encontramos con la concepción teórica que Heller tiene de la "política» y su relación con la cotidianidad, un aspecto que nos parece central y que sintetizaremos rápidamente.

\subsection{Política y «vida cotidiana»}

Para la filósofa, la actividad «política» es aquella «desarrollada con la consciencia del nosotros en interés de una determinada integración... el fin consciente de toda actividad política está siempre acuñado en la integración determinada (polis, Estado, nación, clase, estrato)» (Heller, 1987: 172), y busca ante todo su autorreproducción y perfeccionamiento. La política en la «vida cotidiana» se realiza cabalmente cuando es parte de la reproducción del "particular» en su puesto dentro de la división del "trabajo», es decir, cuando se lleva a cabo una

15. Nos parece importante mencionar brevemente que Heller nunca estudió el pensamiento de Nietzsche, sus reflexiones sobre la «moral» y su "genealogía», lo que nos parece una carencia en sus investigaciones. Como no podemos detenernos a realizar una discusión sobre sus diferencias teóricas, solo dejaremos anotado que entre ambos pensadores hay concepciones opuestas de la moral, ya que para Heller esta siempre es una «actitud espontánea» en la «vida cotidiana» que deviene aprendida de los «sistemas de usos» y que puede cambiar, es un a posteriori, mientras que para Nietzsche la moral es un a priori que ha construido la "tradición» (judeocristiana) y está fundamentalmente ligada al poder. Véase, Friedrich Nietzsche (2011). 
«actividad dirigente» consciente y sistemáticamente en el ámbito de la particularidad, entonces, el "particular» coincide con el «individuo».

Si la «vida cotidiana» no está conectada en algún nivel con la organización y toma de decisiones de la "política», entonces la cotidianidad está condenada al ámbito de la simple reproducción alienada de la sociedad, recluida en el ámbito de la "particularidad», y esta es una de las características de la política en la cotidianidad moderna, donde los "particulares» no deciden sobre su «trabajo», ni les pertenecen las mercancías que producen, ni organizan sus tiempos de producción y descanso, ni los objetivos de la producción, además, la mayor parte de la plusvalía que generan les es expropiada.

Según la filósofa, en algunas comunidades precapitalistas la «vida cotidiana» de los «particulares» se desenvolvía entre lo público y lo privado, participaba de la religión, los ritos y las tradiciones, su «trabajo» les pertenecía igual que lo que producían, por lo tanto, intervenían, directa o indirectamente, en la dirección "política» de la comunidad e influían en la "forma de socialidad», no había una escisión total entre la «vida privada» y la «vida pública».

Con el surgimiento del estado y el desarrollo del capitalismo, comenzó una separación radical entre lo público y lo privado, los individuos fueron confinados en su «vida privada», sometidos a la lógica del trabajo alienado, la «vida pública» comenzó a ser monopolizada por una clase social haciendo de las actividades políticas actividades no cotidianas, los individuos ya no son dueños de su «trabajo» ni de lo que producen, por lo tanto, no influyen en la «forma de socialidad» ni en la dirección política de la sociedad.

En efecto, bajo los regímenes totalitarios como el que vivió Heller, pero creemos también que en las democracias liberales contemporáneas, la actividad política está monopolizada a través de la burocracia, los partidos políticos y las instituciones del estado, la mayoría de la población está alejada de las decisiones que afectan a su «trabajo», su educación, sus «sistemas de usos». En general, la «vida cotidiana» moderna está caracterizada por una separación creciente entre la vida pública y la vida privada, entre work y labour, entre cotidianidad y política. Por lo tanto, para la filósofa, la reunificación entre lo público y lo privado sería un paso, quizás de los más importantes, para avanzar hacia el comunismo, y este proceso ocurre primero en la «vida cotidiana» antes que en las instituciones o el estado.

Con estas tesis, la filósofa hacía una crítica a la «política» (socialista, capitalista, soviética, eurocéntrica) que se imponía a través de los estados nacionales y que se aplicaba sin el consentimiento de la población, e incluso en su contra. Si bien es cierto que están dirigidas implícitamente contra el Gobierno de Hungría que se alineaba a las políticas impuestas por la Unión Soviética, también consideramos que son válidas para los «estados democráticos» capitalistas, pues, para ella, si un estado, o una institución, impone a los "particulares» sus propias normas y valores, entonces se trata de una "dictadura», no importa si se hace en nombre de la «libertad» y la «democracia».

Resumiendo hasta aquí, podemos resaltar al menos seis elementos que Heller destaca para caracterizar la «vida cotidiana». Siguiendo a su maestro 
Lukács: el «lenguaje» y el «trabajo», además, los «sistemas de usos», cada uno de ellos atravesado por la «educación», la «moral» (valores) y la "política» (que en la modernidad se caracteriza por la escisión radical entre la «vida privada» y la "vida pública»).

Estos seis rasgos van a ser complementados en trabajos posteriores, como veremos enseguida, especialmente en sus teorías de las "necesidades» y de los «valores». Sobre su Sociología de la vida cotidiana, nos interesa destacar por el momento que tiene el gran mérito de poner en el centro de la comprensión de la sociedad y del sujeto a la cotidianidad, y considerar su radical importancia para la economía, la política y para el desarrollo de los procesos sociales e históricos.

Su texto es una crítica profunda al socialismo soviético y al de su país, es una toma de distancia de los lineamientos del marxismo ortodoxo y una recuperación del «individuo» y su "vida cotidiana» para la superación de la dominación, además, otorga un grado de «responsabilidad» moral ya no solo a una clase social, el proletariado, sino al conjunto de la humanidad y a cada individuo en particular. Su trabajo busca crear estrategias para enfrentar desde la vida diaria los procesos de alienación de la moral, de la ciencia, del arte y del trabajo, a través de la reflexión filosófica que supere la «moral concreta» de la economía capitalista, que no se ha eliminado en los regímenes socialistas, y que se impone al conjunto de la sociedad. Como veremos a continuación, algunas de estas ideas serán profundizadas en sus trabajos posteriores.

\section{Desarrollo del concepto: historia, valores y «vida cotidiana»}

En Hipótesis para una teoría marxista de los valores, Heller observa que desde sus orígenes la filosofía se ha preguntado por los valores, sus orígenes, relaciones, mérito, funciones y vigencia, sin embargo, es hasta la Revolución francesa cuando hay un intento de componer un concepto universal de "valor». Las causas de esta falta de reflexión son múltiples, pero en general, antes de la modernidad, los valores no eran cuestionados en su funcionamiento, se tomaban como datos «ya dados», o en última instancia eran de origen divino. Con la constitución de la sociedad de clases, el desarrollo de la ciencia y nuevos conocimientos, aunado a los nuevos contactos culturales (América), los valores occidentales se vuelven relativos y van perdiendo vigencia.

En general, la filósofa de Budapest observa que todas las teorías de los valores que se han creado desembocan en tres grandes dilemas: 1) jes el valor derivable u ontológico, o ambos?; 2) ¿en la vida y el pensamiento cotidianos identificamos espontáneamente nuestras preferencias valorativas con los valores como tales?; 3) ¿es posible una ciencia social axiológicamente desvinculada, hay que aspirar a ella? ${ }^{16}$ Heller cree posible resolver estos dilemas con su «teoría

16. La última pregunta es retomada de Weber, a quien Heller recupera y critica por su concepción de "neutralidad valorativa», como más adelante veremos. Para la filósofa marxista, no es posible una ciencia axiológicamente desvinculada, y Weber incluso tiene detrás de sus reflexiones el valor de «verdad». Véase, Ágnes Heller (1974:10). 
marxista de los valores», presentada como una hipótesis que puede ser seguida, pero que no excluye otras hipótesis.

Desde nuestra perspectiva, pensamos que la hipótesis sobre los valores que propone Heller y que se relaciona íntimamente con su noción de «vida cotidiana" se puede comprender mejor en su texto Historia y vida cotidiana, en el cual desarrolla sus principales tesis. El problema central de ese texto, que abarca cotidianidad, historia y valor, es: «iLa historia persigue un fin? Si no persigue ningún fin, ¿̇cuál es el origen de la apariencia de finalidad objetiva? ¿Son conjuntos el desarrollo histórico y la idea de una finalidad objetiva?» (Heller, 1972: 20).

Recuperando sus tesis sobre los «sistemas de usos», la filósofa menciona que en primera instancia el "particular» y la "circunstancia», es decir, la «socialidad», coinciden. Enseguida recuerda que ningún "particular» ha elegido donde nacer y por lo tanto no elige qué "sistemas de usos» tiene que dominar para poder sobrevivir, sino que le están dados a priori. Así, una vez que el particular se ha apropiado de esta "circunstancia» y se plantea «fines» sobre ella, entonces sus actos son «teleológicos», persiguen un fin. De ahí deriva la existencia de múltiples teleologías, en otras palabras, sobre la «circunstancia» se han creado nuevos «valores» que llevan ritmos y direcciones sociales e históricas que pueden llegar a ser antagónicos.

Para Heller, un «valor» es «todo lo que pertenece al ser específico del hombre y contribuye directa o medianamente al despliegue de ese ser específico» (Heller, 1972: 23), es decir, al despliegue de la «libertad», la «felicidad», la "plenitud», posibilidades propias del ser humano, pero, además, es fundamentalmente "un modo de preferencia consciente» (Heller, 1974: 33), no biológico ni natural, sino propiamente reflexivo, «ontosociológico». Desde esta perspectiva, el curso de la historia es idéntico a un proceso de construcción de valores, su crecimiento, degeneración u ocaso.

Como ya observamos, desde la perspectiva marxista de Heller, la «esencia» del ser humano es en primera instancia su socialidad, el trabajo, el lenguaje, la educación, es decir, no se trata de lo que siempre ha estado, sino de «la realización gradual y continua de las posibilidades inmanentes a la humanidad» (Heller, 1974: 27). Así, un «valor» es el enriquecimiento de estos componentes esenciales, es decir, es un compuesto social que se articula histórica y culturalmente, un a posteriori.

El «valor» de la «libertad», observa la filósofa de Budapest, es el valor central de la ética de Marx e incluso quizá del conjunto de la modernidad, pero esto no siempre ha sido así. En la Grecia clásica y quizá en la Edad Media, el valor central era la «felicidad»; es con la sociedad capitalista, especialmente con la Revolución francesa, que la «libertad» cobra un lugar primordial, al mismo tiempo que destruyó la comunidad y sus valores en torno a la «solidaridad».

La visión "progresista» de la historia, vigente desde la Ilustración, proviene de este cambio, pues se interpreta que entre los valores "ganados» y los "perdidos» hay un incremento de «valores» y que así sucede siempre en la historia, pero para Heller la colisión de valores produce que unos decrezcan, otros se 
incrementen y surjan nuevos valores, y esto no significa que el aumento tenga un «fin» por sí mismo: "El despliegue de valores se produce, pues, en esferas heterogéneas, se desarrolla desigualmente y la colisión de esferas es la colisión de valores» (Heller, 1972: 27).

En estos procesos históricos, el «desarrollo de las fuerzas productivas» crece y se potencializa, sobre todo a partir del capitalismo y el desarrollo del libre mercado. Para la filósofa de Budapest, este hecho es central, pues el desarrollo de las fuerzas productivas establece un "criterio de posibilidad" para un incremento de valores, y aunque algunos valores se pierden, como el de la «solidaridad», no desaparecen para siempre, sino que en cualquier momento pueden resurgir.

Heller reconoce explícitamente que en la historia no hay un proceso objetivamente teleológico que lleve al socialismo y al comunismo, esto solo sucede en «apariencia», debido al desarrollo de las fuerzas productivas y el crecimiento de "valores», pues cuando se conquista un "valor» no se vuelve a perder para siempre. Entonces, el «valor» de «solidaridad» se puede volver a conquistar y armonizarlo con el de la «libertad», y esa es la perspectiva del comunismo que practicaba la filósofa de Budapest.

Con relación a la "vida cotidiana», estas observaciones cobran aún mayor importancia ya que es sobre la base de la cotidianidad que se crean valores y es sobre los problemas morales de la vida diaria que se van jerarquizando. La unicidad que se forma entre lo "particular» y lo "genérico» da como resultado la conformación de una sociedad concreta, de unos «sistemas de usos». Una vez que el particular se ha apropiado de ellos, puede transformarlos libremente, dentro de sus propias condiciones y posibilidades históricas, puede adquirir una cierta «distancia» con su «socialidad» y consigo mismo que le permita establecer una «reflexión», una jerarquía y una «elección» más o menos consciente de «valores».

Así surge la pregunta central que llevará después a Heller a proponer su Teoría de las necesidades y su concepto de «revolución» vinculado a la «vida cotidiana»: "¿Qué es necesario para que el hombre pueda elegir con relativa libertad en unas circunstancias dadas?» (Heller, 1972: 90. Las cursivas son mías).

\section{Necesidades, ${ }^{17}$ revolución y «vida cotidiana»}

Junto al concepto de «valor», que contiene una crítica a la visión teleológica de la historia reivindicada por el marxismo soviético, Heller construye su concepto de «necesidad», con el cual le va a dar un giro a la concepción de «sujeto revolucionario» que estableció Marx. El concepto de «necesidad» se propone, entre otros objetivos, establecer la posibilidad de una transformación radical de la

17. Una de las críticas más duras al concepto marxista de necesidad fue formulado por Jean Baudrillard en su texto Crítica de la economía política del signo, publicado en 1972. Debido a que no tenemos espacio aquí para desarrollar la polémica, nos remitimos a un trabajo nuestro anterior: Ulises Márquez (2017), específicamente capítulo 2 y capítulo 4. 
sociedad a través de la participación colectiva de múltiples comunidades e individuos y no solo del "proletariado", como postula la teoría marxista ortodoxa.

Heller retoma tres descubrimientos de Marx sobre la economía política para construir su concepto de «necesidad»: 1) que el trabajador vende su fuerza de trabajo; 2) que se le extrae plusvalía (nueva categoría fundamental); 3 ) el concepto de "valor de uso» adquiere un nuevo significado. Heller menciona que cuando Marx establece que el trabajo produce "valores de uso" es para satisfacer una «necesidad» y que aun en el capitalismo ninguna mercancía (valor de cambio) puede prescindir del «valor de uso». El «valor de uso», en cambio, no requiere del «valor de cambio» para realizarse, entonces, las problemáticas que hay que atender son las siguientes: ¿dónde se origina el «valor de uso» como «necesidad»?, ¿se trata de un problema biológico, instintivo?, ¿en el capitalismo qué define el "valor de cambio» de la fuerza de trabajo?

En el capitalismo el precio de la fuerza de trabajo se establece por el «mínimo" que asegure la reproducción del "particular», es decir, la reproducción de la fuerza de trabajo, mientras que la mayor parte de la riqueza que produce el trabajador toma la forma de "plusvalía», que se apropia alguien más. Sin embargo, dice Heller, ese «mínimo» que asegura la reproducción del trabajador es siempre establecido cultural e históricamente, no se trata solo de un aspecto biológico, sino sobre todo se trata de un «límite» establecido socialmente y ahí radica el centro del cual surgen todas las «necesidades».

Heller reconoce que Marx nunca postuló un concepto de necesidad, y su interpretación se basa en una "actitud valorativa no consciente» (Heller, 1978: 27). Aun así, Marx distingue entre «necesidades naturales» y «necesidades socialmente necesarias», pero esta distinción debe ser aclarada ya que las «necesidades naturales» no pertenecen al ámbito biológico.

Es la sociedad capitalista la que subordina los sentidos humanos a la reproducción biológica reduciendo la vida a mera supervivencia. Es en ese nivel donde se mueven las «necesidades naturales», pero incluso ahí ocurre distinto a la vida animal, ya que en el ser humano se trata de una configuración histórica y social, es decir, incluso satisfacer el ámbito de la supervivencia toma una «forma» social. En síntesis, la «naturaleza» del ser humano es su «socialidad», y esta es siempre configurada históricamente de mil maneras. Con esta afirmación, Heller plantea que no se puede definir al ser humano de manera a priori, no hay ontología, sino «ontosociología».

Para la filósofa, el «trabajo» es el «reino de la necesidad», de modo que con el incremento de la producción y la riqueza crecen las «necesidades», algunas de las cuales podrán ser satisfechas en la misma sociedad, pero nacerán otras que solo podrán ser satisfechas con la superación de las condiciones sociales en las que nazcan. Estas son llamadas por ella «necesidades radicales» $\mathrm{o}$ «necesidades libres», pues pertenecen al «reino de la libertad». En este punto entramos de lleno en su concepción de «revolución» y su «redefinición» del «sujeto revolucionario".

Para desarrollar con profundidad su concepto de "necesidades radicales», Heller lo opone y distingue de la «alienación de las necesidades». Desde su 
óptica, hay cuatro puntos que nos pueden ayudar a comprender el proceso de «alienación» y que resumiremos rápidamente. Un rasgo es que todo fin se convierte en medio y todo medio se convierte en fin hasta el grado máximo opuesto de hacer del otro ser humano un medio para satisfacer fines privados: el trabajador produce valores de uso extraños a él, hasta el punto de convertirse en un "apéndice de la maquina», un simple medio para la extracción de plusvalía. ${ }^{18}$

Otro rasgo del proceso de alienación es que con el crecimiento de la producción económica las «necesidades» dirigidas a la posesión de bienes pueden crecer infinitamente, y hacer de la «desmesura» y el «exceso» un «valor» primordial. Una tercera característica es que todas las necesidades son homogeneizadas bajo el signo del dinero, se disuelven en "avaricia» (acumulación capitalista) o «resignación» (el trabajador solo «necesita» lo suficiente para querer vivir y solo quiere vivir para tener). Por último, el «interés», o mejor la «avidez», surge como categoría filosófica o social, pero no lo es, sino que expresa el modo de producción capitalista que reduce todo al mercado en función de mayor acumulación.

Es en estas condiciones de «alienación», producidas por el desarrollo capitalista, cuando surge la «necesidad» de «trascender» la propia alienación, y aquí la filósofa postula una crítica de Marx y una nueva interpretación del socialismo y el comunismo. Según su perspectiva, una de las contradicciones en la teoría marxista es que establece una relación entre «leyes de la economía» $\mathrm{y}$ "proceso teleológico de la historia», a los que homologa haciendo del "comunismo» un «fin» de la historia. Sin embargo, ella cree que Marx deja entrever en sus postulados que en el camino hacia al comunismo hay varias alternativas, de modo que este se vuelve un «valor» o, en términos kantianos, un «deber», pero no un lugar al que se va a llegar de cualquier modo.

Las «necesidades radicales» nacen a partir de la concepción de la sociedad como una «totalidad» (Marx) que fundamenta en el «sujeto colectivo» el «deber» de la superación de la alienación: con el desarrollo del capitalismo, la «miseria» y las condiciones de explotación crecen, y con ellas emergen las «necesidades radicales». Su cumplimiento no solo es un «deber», sino que las personas las tienen que realizar «so pena de perecer si no se han de ver satisfechas» (Heller, 1974: 94).

El punto central del análisis marxista está en el «sujeto revolucionario». Para Marx, el "proletariado» era el único «sujeto» capaz de superar al capitalismo, y en ese proceso liberar a toda la humanidad de la alienación, pero Heller observa que de ello no se desprende que realmente el proletariado quiera liberarse y que realmente sus necesidades sean radicales y que no posean fines "particulares».

Para nuestra filósofa, las «necesidades radicales» se engendran también en otros «sujetos» colectivos, a los que llama «comunidades de libre elección»,

18. Sobre este punto, Heller observa que en Marx aparece el concepto de «necesidades imaginarias» o «caprichos», sin embargo, para la filósofa de Budapest, no existen necesidades imaginarias, sino que las necesidades «normales» y las «refinadas» (con acento negativo) dependen de los valores que una sociedad establezca sobre «normalidad». Lo que sí que existe, observa Heller, son las «necesidades manipuladas», o la "manipulación de las necesidades», idea que solo se insinúa en Marx. 
en las que pueden participar una pluralidad de actores sociales, académicos, feministas, estudiantes, colectivos, organizaciones, que no necesariamente son «proletarios» u «obreros», con ello abre las posibilidades para seguir con la construcción del comunismo.

Esta apuesta por el comunismo cambiará en los siguientes años, sobre todo después de su exilio, pero no cambiarán sus ideas sobre las «necesidades radicales» como posibles fuentes de superación de la alienación, y eso es explícito en su texto de 1996 Una revisión de la teoría de las necesidades, cuando lleva casi veinte años exiliada. Sinteticemos rápidamente algunas de sus autorrevisiones.

En principio, uno de los cuestionamientos centrales que se le hacen a Heller después de la caída del bloque soviético y tras años de exilio es si aún sigue creyendo en los principios políticos y éticos del «socialismo» y del «comunismo» que reivindicaba en los años de su vida intelectual en Hungría. Para tratar de responder a este cuestionamiento, plantea tres principios básicos que añade a su teoría de las necesidades: la ontología, la ética y la política.

La pregunta que está en el centro de su teoría es: jexisten necesidades «verdaderas y necesidades "falsas? Para ella, no existe tal distinción, no se puede aceptar que exista un "teórico» o una «institución» que dicte cuáles son verdaderas o no, aceptar esto significaría que a «individuos» y "particulares» se les impongan literalmente sus «necesidades» y esto constituiría una «dictadura sobre las necesidades», lo que lleva al totalitarismo del pensamiento y de las instituciones.

Para evitar este impasse teórico y este peligro práctico, la filósofa no hablará de necesidades reales o imaginarias, ni falsas o verdaderas, para ella «todas las necesidades sentidas como reales son reales» (Heller, 1996: 60), y por lo tanto deben ser reconocidas jerárquicamente, es decir, es en la "vida cotidiana» donde se establece cuáles son las «necesidades urgentes», y este es el «aspecto ontológico", no se trata de un a priori sino de un a posteriori, que se da en la socialidad, por lo tanto cambian.

En un segundo momento, si todas las «necesidades» han de ser reconocidas como «reales», esto no significa que todas las necesidades sean «buenas», a decir de Heller, la necesidad de explotar y dominar al otro es tan «real» como la necesidad de liberarse de la explotación. La única solución teórica y práctica posible es la «norma ética» base del «imperativo categórico» kantiano y la lucha contra las tres «ansias»: posesión, dominación y ambición. Sobre este punto específico, la filósofa es irreductible, no hay «leyes» a priori que garanticen por sí mismas la convivencia sin dominación ni explotación, sino que se requiere siempre de la participación consciente del «individuo», de la "ética».

El tercer aspecto se refiere a la "política» y la siguiente pregunta: jes posible una interpretación del mundo en la que se pueda evadir «lo bueno" y lo «malo»?, es decir, ¿se puede elegir entre una «forma» de vida u otra y considerar la elección en términos no valorativos? Para Heller, esto no es posible, ya que toda decisión e interpretación se dan en términos de los "valores» vigentes en una sociedad. Entonces la discusión debe centrarse en la posibilidad de que el «sistema de necesidades humanas» en una sociedad específica sea producto de una elección consciente de "valores», o sea de una decisión "política», en 
otras palabras, que la gente influya y determine la formación del sistema y elija conscientemente en comunidad cuáles son sus necesidades prioritarias.

Estos tres aspectos de la teoría de las necesidades (ontológico, ético y político) llevan a la «alternativa» de las «necesidades radicales», que han de servir como base para la superación de la alienación. Pero la misma Heller pregunta: ¿estas necesidades no son también «ideológicas»?, ¿la utopía que soportan no contiene rasgos ideológicos? Para ella, la solución teórica está contenida desde el principio de que todas las necesidades deben ser reconocidas como «reales», y por lo tanto también las «necesidades radicales» son sumamente plurales, y ningún movimiento (feminista, campesinos, obreros, estudiantiles) las abarca todas, pero sí que todas excluyen incluir al «otro» como mero medio para fines, es decir, si un movimiento actúa contra la voluntad de «otro», deja de ser radical, independiente de sus ideas. Y definitivamente todas las necesidades tienen momentos ideológicos.

Según este nueva perspectiva de Heller, más allá del estado socialista o capitalista, la labor de una institución de aspiraciones democráticas debe ser buscar crear oportunidades iguales para necesidades distintas y sistemas de necesidades cualitativamente diferentes, lo que implica el deber de criticar aquellas necesidades que impidan el libre desenvolvimiento de la esencia humana y que hacen del "otro" un mero «medio». Esta crítica debe ocurrir tanto socialmente como personalmente: «El Estado democráticamente pluralista y su sistema de instituciones no puede ser la fuente para la elaboración de nuevos sistemas de necesidades y nuevas formas de vida. Más aún, no debe convertirse en su fuente, solo puede establecer una estructura para todo esto» (Heller, 1996: 81).

Aun así, Heller sigue pensando que lo más importante es la organización de la sociedad, de los «individuos», para influir en la "vida pública» y que esta no sea monopolio de una clase social. Después de sus años de exilio y de la caída del bloque soviético, sigue convencida de que es necesario enfrentar la dominación y la explotación a través de la «sociedad civil» (Hegel) organizada:

Haciendo la guerra civil permanente cada vez más equitativa, la sociedad civil también la mantiene en paz. Al poner en duda la justicia de la distribución presente de las necesidades, algunos grupos de la sociedad civil emplean la fuerza, e incluso la violencia, pero el baño de sangre es raro. No obstante, cuando la gente pierde su confianza en la impugnación de la distribución de necesidades por la sociedad civil, el baño de sangre aparece de nuevo en la agenda de la guerra. (Heller, 1996: 265)

\section{Conclusiones}

Las reflexiones de Ágnes Heller sobre la «vida cotidiana» se mueven entre distintas perspectivas disciplinarias (filosofía, sociología, historia, economía, antropología), y en general se suscriben a una perspectiva marxista que en el transcurso de los años se va diluyendo hasta que parece desaparecer. Sin embargo, creemos poder constatar que, a pesar de los cambios de sus perspectivas, 
hay continuidades teoréticas, desde Sociología de la vida cotidiana y la primera versión de la Teoría de las necesidades hasta su revisión de 1996.

Por ejemplo, durante todos estos años la filósofa discute el concepto de «necesidades», por medio del cual realiza una crítica a los sistemas totalitarios, fascistas, socialistas y liberales, que imponen una «dictadura de las necesidades». Asimismo, en el centro de esta reflexión antropológica y sociológica, está la "vida cotidiana», a la que le da un lugar central para comprender los procesos históricos y culturales y de la que destaca su importancia para las ciencias sociales y humanas.

Según Lindón (1999), existen tres grandes vertientes en los estudios de la "vida cotidiana»: 1) la que considera a la cotidianidad como el lugar de la alienación (aquí ubica a Ágnes Heller); 2) la que la considera como el lugar de la invención y las resistencias (aquí ubica a Michel de Certeau), 3) una vertiente que combina las dos primeras (ella se autoubica en esta última). Desde nuestra perspectiva, consideramos que Lindón se equivoca al colocar a Heller en la categoría en la que la «vida cotidiana» es el lugar de la alienación, antes bien, la filósofa de Budapest es una de las primeras pensadoras del siglo xx que pondera la cotidianidad como el principal lugar en el que se inicia la «revolución», noción que se distancia del marxismo ortodoxo de su época.

Asimismo, además de los influjos y debates que provocó en la academia y las ciencias sociales y humanas, dentro del marxismo y fuera de él, Heller también causó influencias en algunos movimientos sociales y en el feminismo que se desarrolló, sobre todo en Europa, después de 1968. Martínez Mellado (1998) comenta que nuestra autora, durante sus años como teórica marxista en Hungría, nunca separó la lucha socialista de la emancipación de la mujer, y concebía la relación entre los géneros dentro del esquema general de la crítica de la alienación. Según esta interpretación, en el texto de Heller La revolución de la vida cotidiana se esbozaba la idea de que las relaciones de subordinación entre hombres y mujeres serían superadas en el comunismo.

Consideramos que Martínez Mellado se equivoca, pues creemos poder observar que desde su obra Teoría de las necesidades, escrita y publicada durante sus años de vida en Hungría, ya esboza la lucha social en términos de las "necesidades radicales», cuya satisfacción se da primero dentro de un proyecto de vida personal, antes que a través de las instituciones o el Estado. En ese trabajo, ya está pensando en los diferentes actores sociales (mujeres, estudiantes, académicos, artistas) que luchan contra la alienación de la «vida cotidiana", pero incluso desde Sociología de la vida cotidiana, cuando establece la distinción entre "particular» (alienado) e «individuo" (no alienado), ya está pensando en otros «sujetos revolucionarios» distintos al "proletariado». Estas ideas se hacen explícitas a su salida de Hungría. Por ejemplo, en unas conferencias que dio a principios de 1980 y que fueron publicadas bajo el título Para cambiar la vida, comentó que las luchas feministas son importantes para la transformación de las relaciones de alienación y que «las mujeres logran elaborar mucho mejor sus convicciones si están con otras mujeres» (Heller, 1981: 178). 
Desde nuestra perspectiva, uno de los principales problemas que detecta Heller en la «vida cotidiana» moderna es la separación radical entre «vida privada» (personal) y «vida pública» (política), con la cual «particulares» e «individuos» son alejados de la toma de decisiones políticas, económicas, culturales y educativas, de modo que se impone una "moral concreta» (la moral capitalista) al conjunto de la sociedad. Es en este marco que el «individuo» lucha contra la «alienación» en su vida diaria, independiente del Estado y las instituciones, pero también en ellas y contra ellas. En este punto, Heller parece coincidir con el pensamiento de Carol Hanisch cuando en 1969 manifestaba que «lo personal es político».

Sin duda, muchos de los problemas del siglo xx que detecta Heller siguen persistiendo en nuestra época, y el reto de la "superación" de la escisión radical entre «vida privada» y "vida pública» sigue pendiente. Así, nos parece importante plantear esta problemática sobre la base de estas reflexiones: ¿debemos abandonar la idea de que es posible evitar la concentración económica y el monopolio de la política?, ¿es inimaginable superar la «dictadura de las necesidades"? Creemos que sí es posible una "política» en la cotidianidad, que se puede redistribuir la concentración económica y que es viable enfrentar diariamente la «dictadura de las necesidades», por lo tanto, postulamos que estas reflexiones hellerianas son vigentes para realizar un estudio contemporáneo de la "vida cotidiana» en nuestras sociedades problematizando y analizando cómo se configura la separación entre lo público y lo privado, o, dicho de otra manera, estudiando la relación entre cotidianidad y "política», sus principales rasgos y características, problemáticas y posibles alternativas sociales.

Otro de los problemas relevantes que detecta Heller y que nos brindan claves para la interpretación y comprensión de nuestras sociedades contemporáneas es la relación entre cotidianidad y ética, y por lo tanto la relación entre "procesos históricos» y «elección de valores». En este ámbito sería sumamente interesante investigar cuáles son los principales «valores» que enmarcan lo cotidiano en nuestros días y cuál es la «moral» que domina nuestros sistemas «concretos», ¿coincide con los «valores abstractos»?

Otro tema central en la reflexión de Heller sobre la «vida cotidiana» es la "educación», un aspecto básico para la enseñanza y la «apropiación de los sistemas de usos» en cada sociedad. En este punto, su concepción plantea dos grandes polos. Por un lado, la educación como «sistema funcional» que permite la reproducción y la autorreproducción del «particular» y de su socialidad; por otro lado, como "pedagogía crítica", que promueve una "conquista» de la «individualidad» para la transformación social y la realización de los «valores abstractos» (libertad, felicidad, igualdad) en la cotidianidad "concreta».

Ambas pedagogías no son mutuamente excluyentes, sino que en el contexto sociohistórico de Heller predominaba una pedagogía funcionalista al servicio del estado y la economía. Considerando esta experiencia histórica, una problemática que nos parece vigente y que nos debería interpelar directamente 
es la siguiente: ¿qué tipo de «educación» (funcionalista o crítica) se transmite y predomina en nuestra "vida cotidiana»?, ¿por medio de qué instituciones o procesos se transmiten los «sistemas de usos»?

Un último punto que nos interesa destacar en Heller es su concepción antropológica esbozada en su texto Instinto, agresividad y carácter, escrito y publicado antes de su exilio (1978). De manera resumida, plantea que el anthropos no es un ser "benigno», como afirma Eric Fromm, ni es un ser «maligno», como piensa Konrad Lorenz, sino que en el ser humano no hay nada definido a priori, su principal característica es su "plasticidad» infinita: «El hombre no posee absolutamente ningún instinto agresivo —ni defensivo ni ofensivo, ni benigno ni maligno. El hombre no es en ningún aspecto un ser gobernado por los instintos» (Heller, 1994: 34). ${ }^{19}$

Desde nuestra perspectiva, este tesis es crucial porque deja «abiertas» las posibilidades del «conocimiento» del propio ser humano, de su "naturaleza», de su cultura, de su historia y, sobre todo, de su porvenir, su futuro inmediato y distante. Esta postura rompe con cualquier «esencialismo» y «ontología» que pretenda definir al anthropos de manera a priori y acote sus procesos sociales a «leyes», «normas» o «tendencias», o bien los reduzca a la economía, la política o la psicología.

Para nosotros esta es una postura teórica que merece ser recuperada para cualquier comprensión sociológica, pues ninguna teoría o estudio social puede postular una «verdad» absoluta, sino solo aproximaciones, pero también para comprender que siempre es "posible» una sociedad distinta, en la cual no imperen las relaciones sociales de dominación, ni las grandes concentraciones económicas, ni el monopolio de la política, donde la «vida cotidiana» tenga cada vez más una influencia directa en la "forma» de socialidad, la elección de «valores», «necesidades» y el devenir los procesos sociohistóricos y culturales.

Ágnes Heller murió en 2019, y su obra es un «testamento» de su época, de su experiencia como mujer, judía, nacida en pleno ascenso del nacionalsocialismo, que sobrevivió a la Segunda Guerra Mundial en la clandestinidad, que resistió a la represión estalinista y soviética durante treinta años, que fue perseguida y hostigada por el gobierno socialista húngaro, y a quien se le prohibió dar clases en la universidad y publicar. En Europa ningún país le dio asilo político y tuvo que irse a Australia y posteriormente a Estados Unidos. Por último, al final de su vida pudo regresar a Hungría, donde murió a los 90 años. Su «vida cotidiana» es un "espejo de la historia» de su época, y sin duda muchas de sus aportaciones siguen siendo vigentes para los estudios sociales, políticos, económicos de nuestras sociedades, y merecen ser recontextualizadas y críticamente recuperadas. Este escrito constituye un esfuerzo en esta dirección.

19. En esta tesis hay un parecido a la «antropología de la ambigüedad» que construye Lluís Duch. Para este autor, el ser humano no es ni bueno ni malo a priori, sino que es «ambiguo» y se define siempre a posteriori, es decir, en la acción. Véase, Lluís Duch (2000; 2002). 


\section{Financiamiento}

Consejo Nacional de Ciencia y Tecnología (CONACyT-México), en el marco de Estancia Posdoctoral en la Universidad Autónoma de Barcelona, 2018-2020.

\section{Referencias bibliográficas}

Aguirre, Ángel (1996). «Introducción a la teoría de las necesidades». En: Heller, Ágnes (1996). Una revisión de la teoría de las necesidades. Barcelona: Paidós.

Berger, Peter y Luckman, Thomas (2003). La construcción social de la realidad. Buenos Aires: Amorrortu Editores.

Castillo Jairo, Rosa (2007). «Ivan Petrovich Pavlov. Una aproximación a su vida y obra». Revista de Psicología Cientifica (9) 37. Disponible en <https://www.psicologiacientifica.com/ivan-petrovich-pavlov-vida-y-obra/>.

Duch, Lluís (1998). Mito, interpretación y cultura. Aproximación a la logomítica. Barcelona: Herder.

- (2000). Llums i ombres de la ciutat. Antropologia de la vida quotidiana 3. Montserrat: Publicacions de l'Abadia de Montserrat.

- (2002). Antropología de la vida cotidiana. Simbolismo y salud, I. Madrid: Editorial Trotta.

Freud, Sigmund (2001). El malestar en la cultura. México: Colofón.

García Cotarelo, Ramón (1977). «La Escuela de Budapest». Revista Española de la Opinión Pública, 49, 188-193.

HeIDEgGer, Martin (2003). Ser y tiempo. Madrid: Editorial Trotta.

Heller, Ágnes (1972). Historia y vida cotidiana. Aportaciones a la sociología socialista. Barcelona: Grijalbo.

- (1974). Hipótesis para una teoría marxista de los valores. Barcelona: Grijalbo.

- (1978). Teoría de las necesidades en Marx. Barcelona: Península.

- (1981). Para cambiar la vida. Barcelona: Crítica.

- (1987). Sociología de la vida cotidiana. Barcelona: Ediciones Península.

- (1994). Instinto agresividad y carácter. Barcelona: Ediciones Península.

- (1996). Una revisión de la teoría de las necesidades. Barcelona: Paidós.

- (1998). La revolución de la vida cotidiana. Barcelona: Ediciones Península.

Lefebvre, Henri (1947). Critique de la vie quotidienne. París: Editions Bernard Grasset.

- (1961). Critique de la vie quotidienne II. Fondements d'une sociologie de la quotidienneté. París: L'Arche.

- (1973). El derecho a la ciudad. Barcelona: Editorial Península.

- (1980). La vida cotidiana en el mundo moderno. Madrid: Alianza Editorial.

- (1981). Critique de la vie quotidienne III. De la modernité au modernisme (Pour une métaphilosophie du quotidien). París: L’Arche.

- (2013). La producción del espacio. Madrid: Capitan Swing.

Lindón Villoria, Alicia (1999). De la trama de la cotidianidad a los modos de vida urbanos: el Valle de Chalco. México: El Colegio de México-El Colegio Mexiquense.

Lukács, György (1966). Estética. La peculiaridad de lo estético, 1. Barcelona-México: Ediciones Grijalbo, SA.

Márquez, Ulises (2017). El estudio de la vida cotidiana a través de tres perspectivas teóricas: del materialismo histórico de Henri Lefebure y Ágnes Heller a la antropologia simbólica de Lluis Duch. Tesis de doctorado. México: Universidad Nacional Autónoma de México. 
Nietzsche, Friedrich (2011). Genealogía de la moral. Madrid: Alianza.

SÁnDOR, Márai (2006). Tierra tierra. Barcelona: Salamandra.

Martínez Mellado, Asunción (1998). «Ágnes Heller y el feminismo». Revista de Filosofia, 17, 177-184.

Pérez Quintana, Antonio (2005). «Ágnes Heller: una filosofía de la libertad, una ética de la elección». Revista Laguna, 16, 117-144.

Prior, Ángel (2002). Axiología de la modernidad: ensayos sobre Ágnes Heller. Madrid: Frónesis. 